\title{
Exploring Degree of Awareness about Health Care and Hygienic Practices in Secondary School Students Residing in Semi-urban Areas of Bangladesh Ali $\mathrm{MY}^{1}$, Rahman $\mathrm{MM}^{2}$, Siddiqui $\mathrm{MH}^{3}$
}

\begin{abstract}
This cross-sectional descriptive study evaluated the general health knowledge and practices of hygiene among semi-urban school children in Bangladesh and assessed the extent to which proper knowledge of hygiene was associated with personal hygiene characteristics. The study population was limited within mature students of class VIII and class X, which were randomly selected. The objectives of the study was first to assess the health knowledge acquired and health care practice undertaken by the students and finally to assess needs for improvement so that they could enjoy a better living and quality life. A well written pre-tested questionnaire was supplied to each student under study. Data were collected and analyzed using Computer Excel Program. The result of the study revealed that approximately $59 \%$ of students were classified as having little or no idea or knowledge of health. The majority of the respondents (44.95\%) considered early going to bed. Only $11.01 \%$ respondents mentioned that they liked to go to bed at late hours after $11 \mathrm{pm}$. Regarding awakening time, $94.92 \%$ respondents in favor of get up early in the morning before sunrise, but actually $36(15 \%)$ habituated to get up early in the morning before the sun rise and a great number $200(84.74 \%)$ were habituated to late rise. A great number of students (78.81\%) were in favor of taking home-made foods and majority respondents considered these foods as safe and wholesome. More than $98 \%$ respondents admitted that street vender foods were unhygienic and might cause intestinal disturbances, nausea, vomiting and worm infestation. 100\% respondents had access to drink tube well water and it was safe and portable according to $84.75 \%$ respondents. To mention about access to proper and adequate defecation facilities it was reported that $90.68 \%$ students had the habit to use sanitary latrines. A very low percent of respondents $(4.24 \%)$ used soap for washing of hands after defecation. About $95.76 \%$ of students reported that they washed their hands with water only and soaps were seldom used. The findings with respect to oral hygiene practice, $55.08 \%$ respondents preferred to brush teeth. A good number of respondents $50.85 \%, 20.34 \%, 15.25 \%, 8.47 \%$ and $5.08 \%$ used ash, followed by neem stick, tooth paste, Kalo Majon and magic tooth powder respectively. Although $87.29 \%$ of respondents never smoked, but it is very undesirable that more than $10 \%$ of students developed smoking habit. The present study revealed that $83.00 \%$ of respondents were in favor of keeping nails short. Regarding personal cleanliness $14.83 \%$ of the students reported not taking bathing regularly. About $83 \%$ realized the importance of wearing underwear. Lastly, the students under interview although clearly stressed upon the need of regular exercise which is good for health, but quite a big number of respondents (91.53\%) were not inclined to take exercise regularly.
\end{abstract}

CBMJ 2013 Jan: Vol-02, No-01: P: 55-62

Key words: Knowledge, Personal hygiene, Health care practices, school students.

\section{Introduction}

Good hygienic care as well as practices in terms of personal hygiene contributes to a large extent on factors relating to healthful living and prevention of hazards from diseases. It is the central task in the core domains of work and activities of health and hygiene $^{1}$. These health risk factors are directly related to some important daily activities implicated with worthy operational actions and obligatory responsibilities, such as (i) washing hands before meals and after
1. * Dr. Md. Yunus Ali

Associate Professor of Community Medicine, Community Based Medical College Bangladesh

2. Prof. Dr. Md. Muzibar Rahman Head of Dept. of Biochemistry Community Based Medical College Bangladesh

3. Dr. Mahmud Hasan Siddiqui Assistant Professor of Ophthalmology Community Based Medical College Bangladesh

\footnotetext{
* Address of Correspondence: e-mail: dryunusali@yahoo.com mobile: 0088-01711-315742
} 
defecation with soap (ii) brushing teeth at least twice a day specially after breakfast and after meals (iii) eating timely safe foods (iv) early to rise and early to bed (v) taking bath with soap regularly (vi) taking regular exercise (vii) keeping nail short .only washing hands with soap prevents many gastro intestinal spacially diarrhoeaP ${ }^{2 \mathrm{P}}$. To raise awareness on the issue the UN children's fund is launching the first Global Hand -washing day on wednesday Oct $14,2008 \mathrm{P}^{2 \mathrm{P}}$. It is now high time to put focus on aspects of health care hygienic practices as defined in national health care and sanitation strategy.

Hygiene promotion interventions contribute to enhance health care knowledge level of people at all levels. However it is unfortunate that despite significant efforts made by different development partners and NGOs, overall achievements assumed are not satisfactory in Bangladesh. It is therefore a felt necessity to get access to information on simplified hygiene messages and issues and develop a dynamic integration of a prerequisite condition to adopt hygienic behaviors and sustain the same. Schools were identified as a center for development including hygiene and sanitation in society primarily by UNICEF because it is the entry point for a life-long learning process regarding sanitation and hygiene behavior and school children are important "change catalyst" for influencing societal behavior. Although the lessons learnt and key issues and challenges are varied, but among these washing hands in critical times are good ways of avoiding intestinal diseases ${ }^{2 \mathrm{P}}$ and has been emphasized in hygiene promotion in Bangladesh for several years. Realizing the sheer necessity of the issue of personal health care and hygienic practices, Government of Bangladesh has very recently circulated directives for ensuring environmental sanitation focusing on washing both hands at six critical times. All primary and secondary schools started disseminating the messages so that the community members would be in a position to know the aspects of health care and sanitation and start practicing them in order to maintain their personal hygiene and cleanliness. 50 percent diseases could be avoided if mothers and children adopted the habit of hands washing with soap before eating and after toilet use which can save more lives than any single vaccine or medical intervention $P^{3,4 \mathrm{P}}$. Hand washing with soap has been reported to reduce diarrheal morbidity by $44 \%$ and respiratory infections by $23 \%{ }^{5,6 P}$. Hygiene related diseases in Bangladesh costes 5 billion taka each year for treatmentP ${ }^{7} P_{\text {and }}$ "The economic impects of inadequate sanitation in Bangladesh 2012" study shows it costs 4.2 Billion US dollars. In view of the above fact the objectives of the present investigation have been linked to a series of collected information profiles with regard to knowledge of health care status of secondary school students and assess the extent to which proper knowledge on hygiene practices is associated with personal hygiene characteristics among semi-urban school children in Bangladesh. Information from this study will serve as baseline data for future hygiene intervention programs to mitigate the crisis and focus the way to overcome the critical situation.

\section{Methods}

A cross sectional type of descriptive study was conducted within a population belonging to secondary school students residing in semi-urban area. A total of 236 students were brought under this study and they were selected randomly from Class VIII and Class $X$. These students are quite mature to understand and give appropriate answers to questions that were asked with regard to their knowledge about health status and personal hygienic practices. Students absent during the survey period (august/2010) were excluded. An easy to understand structural questionnaire in native language was put to each student under this study. The interviews were designed to uncover information about the practices, experiences, motivations and approaches of the students under study. They were asked to think properly before filling up the blanks and give an appropriate answer. The objectives of the study were communicated to the students and participation was completely voluntary. Study participants provided oral consent prior to participating and there was a 100\% participation rate.

The questionnaire consisted of frequencies of bathing, washing hands, brushing teeth, 
defecation habit, use of drinking water, and teeth cleaning (pastes, twigs, majon, powder etc). Other questions included washing hands (after defecation, before meals, after meals); materials used for hand washing (soap and water, water only); hand washing preference (before meals, after meals, do not know); and hand washing importance (after defecation, before meals, after meals). Individual hygiene for clean fingernails (no, yes); trimmed fingernails and the individual condition of underwear clothing and presence of scabies, cuts, and bruises and knowledge about sanitation were also assessed. The data comprised information about the interventions contributing to daily operational activities of health care and hygienic practices that they implement within the framework of each individual's personal hygiene. The filled questionnaires were collected and the data containing information were first grossly processed and later entered in the computer for analysis using Excel Program.

\section{Results}

Table I: Percentage distribution of respondents towards health care profiles and operational activities of hygienic practices

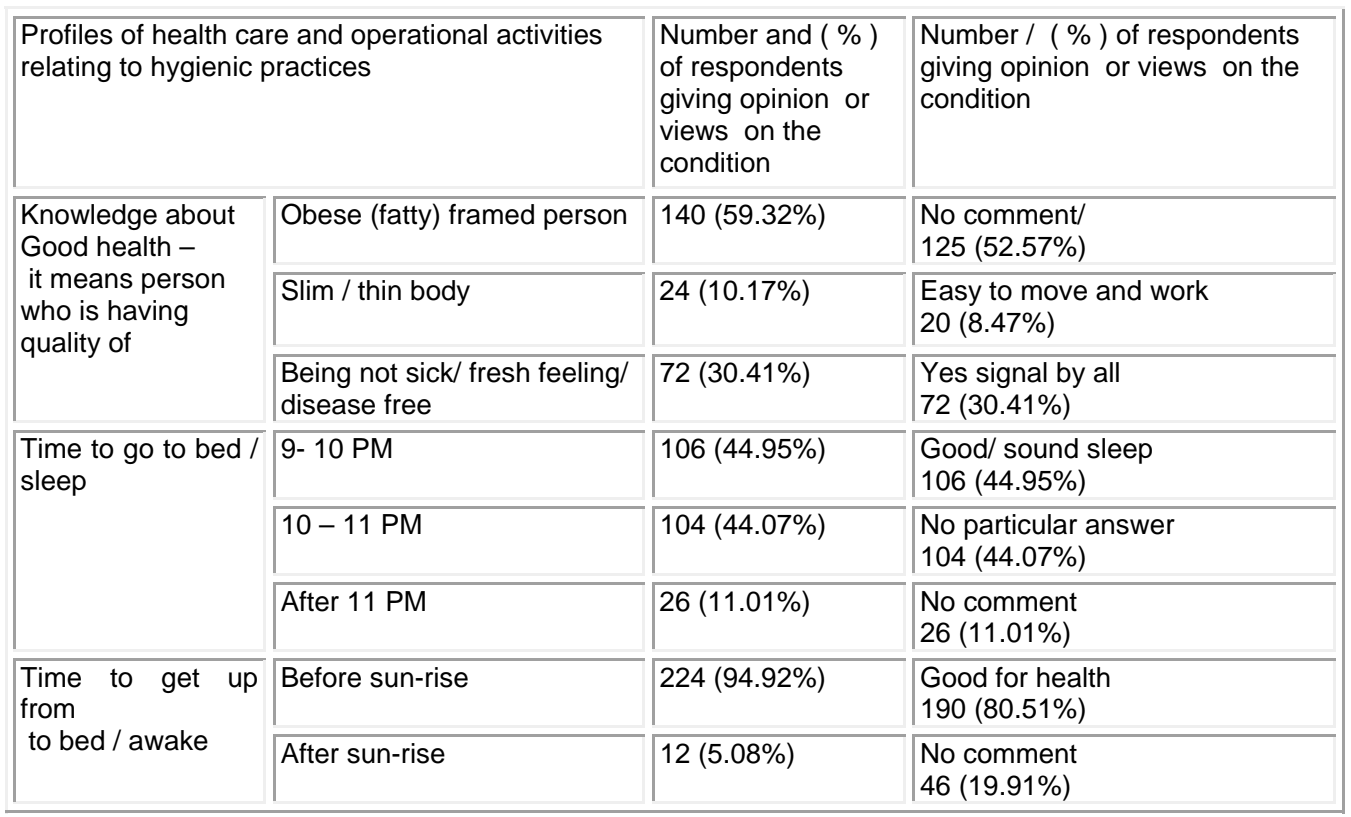

The result revealed that approximately $59 \%$ of students were classified as having little or no idea or knowledge of health. They meant a fat and obese person as healthy, but they made no comment about any benefit of becoming fatty. One third of the students differed from this and according to them a healthy person should not become sick and they should be disease free. They were of the idea that person without disease felt fresh and did not get disease. Only about $10 \%$ respondents gave their opinion in favor of slim or thin person as healthy. They found that slim people could move and perform work easily. Regarding sleeping and awakening time the percentages of students reported the preference for bed time.

The majority of the respondents (44.95\%) considered early going to bed. They preferred the sleeping time between $9 \mathrm{pm}$ to $10 \mathrm{pm}$ because they got good sound sleep if they would go to bed at the early part of night. Although almost the same number of respondents (43.22\%) were in favor of going to bed a little late hour, which is between $10 \mathrm{pm}$ and $11 \mathrm{pm}$, but they could not give any good reason for this sleeping time. Only $11.01 \%$ respondents mentioned that they liked to go 
to bed at late hours after $11 \mathrm{pm}$. However they could not put forward any substantial beneficial effect in favor of this sleeping time. Regarding awakening time $94.92 \%$ respondents gave their opinion to get up early in the morning before sunrise, but only a small percentage $(5.08 \%)$ were put opinion to late rise to get up after the sunrise. It is interesting to note that the majority of the respondents (80.51\%) were aware of the importance of early rise from bed and indicated its benefit as good for health.

Table - II: represents the percentage distribution of respondents towards knowledge about personal hygiene profiles (eating, drinking, defecation habits).

\begin{tabular}{|c|c|c|c|c|}
\hline \multicolumn{3}{|c|}{ Profiles of personal hygiene practices } & \multirow{2}{*}{$\begin{array}{l}\text { Number and }(\%) \text { of } \\
\text { respondents to personal } \\
\text { hygiene practice profiles }\end{array}$} & \multirow{2}{*}{$\begin{array}{l}\text { Number and (\%) of } \\
\text { respondents view about } \\
\text { personal hygiene practice } \\
\text { benefit }\end{array}$} \\
\hline \multirow{7}{*}{$\begin{array}{l}\text { Knowledge } \\
\text { about } \\
\text { personal } \\
\text { habit }\end{array}$} & \multirow{2}{*}{$\begin{array}{l}\text { Eating } \\
\text { habits }\end{array}$} & Home-made food & & \\
\hline & & $\begin{array}{l}\text { Street vendors open } \\
\text { food }\end{array}$ & 50 ( $21.19 \%)$ & $\begin{array}{l}132(55.93 \%), \text { Diarrhea } \\
15(6.36 \%), \text { worm infestation } \\
89(37.71 \%), \text { no answer }\end{array}$ \\
\hline & \multirow[t]{3}{*}{$\begin{array}{l}\text { Drinking } \\
\text { habits }\end{array}$} & $\begin{array}{l}\text { Tube well or supply } \\
\text { water }\end{array}$ & $236(100 \%)$ & $200(84.75 \%)$, it is safe \\
\hline & & River or pond water & $0(0 \%)$ & No opinion \\
\hline & & $\begin{array}{l}\text { Bottled water, } \\
\text { Soft drinks } \\
\text { (occationally) }\end{array}$ & $\begin{array}{l}136(15.25 \%) \\
115(48.72 \%)\end{array}$ & $\begin{array}{l}20(8.47 \%) \text { No germ } \\
85(36.01 \%) \text { good and } \\
30(12.71 \%) \text { as fashion }\end{array}$ \\
\hline & \multirow[t]{2}{*}{$\begin{array}{l}\text { Defecation } \\
\text { habits }\end{array}$} & $\begin{array}{l}\text { Use of Sanitary } \\
\text { latrine }\end{array}$ & $214(90.68 \%)$ & $\begin{array}{l}98(41.43 \%, \text { good } \\
56(23.73 \%) \text { no disease } \\
\text { occur } \\
82(34.73 \%) \text { no answer }\end{array}$ \\
\hline & & $\begin{array}{l}\text { Unsanitary or open } \\
\text { field latrine }\end{array}$ & $22(9.32 \%)$ & None answered \\
\hline
\end{tabular}

A great number of students (78.81\%) were in favor of taking home-made foods and majority respondents considered these foods as safe and wholesome. Although only one-fifth of the respondents gave their opinion for taking street foods, but it is remarkable that more than $98 \%$ admitted that these foods were unhygienic and might cause intestinal disturbances, nausea, vomiting and worm infestation. The present study revealed the drinking habit of students. It was found that a large number of respondents $(84.75 \%)$ had great access to drinking tube well water or supply water which was according to them safe and potable. None of the respondents' sources of drinking was river or pond water. It is interesting to mention here that bottled drinking water and soft drinks cola etc were used only very occasionally by only about $48 \%$ respondents. To mention about access to proper and adequate defecation facilities it was reported that $90.68 \%$ students had the habit to use sanitary latrines and that more than $90 \%$ respondents identified this practice as hygienic as there were fewer occurrences of diseases. A very small number of respondents $(9.32 \%)$ lack access to proper and adequate defecation facilities.

Table III shows the percentage distribution of respondents towards profiles of activities of personal hygienic practices. The most important task of personal hygiene is washing of hands before taking of meals and after defecation. It is evidenced that this habit is very poorly practiced by the students. 
Original Article

Table III: Percentage distribution of respondents towards profiles of activities of personal hygienic practices

\begin{tabular}{|c|c|c|c|c|}
\hline \multirow{24}{*}{$\begin{array}{l}\text { Activities } \\
\text { of } \\
\text { Personal } \\
\text { Hygiene } \\
\text { Practices }\end{array}$} & \multirow[t]{2}{*}{$\begin{array}{l}\text { Hand washing } \\
\text { habit }\end{array}$} & $\begin{array}{l}\text { Before taking of } \\
\text { meals }\end{array}$ & $\begin{array}{l}\text { using of soap } 8.47 \% \\
\text { using water only } 91.53 \%\end{array}$ & $\begin{array}{l}27.54 \% \text { good } \\
72.46 \% \text { no comment }\end{array}$ \\
\hline & & After defecation & $\begin{array}{l}\text { using of soap } 4.24 \% \\
\text { using water only } 95.76 \%\end{array}$ & $\begin{array}{l}\text { 85.59\% Less disease } \\
\text { 14.14\% no opinion }\end{array}$ \\
\hline & \multirow{10}{*}{$\begin{array}{l}\text { Tooth brushing } \\
\text { habit }\end{array}$} & \multirow{5}{*}{ Time of brushing } & 87 (36.86\%) Morning & $102(43.22 \%)$ good teeth \\
\hline & & & 08 (3.39\%) Mid-day & $08(3.39 \%)$ no answer \\
\hline & & & $110(55.08 \%)$ bed time & $110(55.08 \%)$ good teeth \\
\hline & & & $188(79.70 \%)$ before meals & $200(85 \%)$ good habit \\
\hline & & & $22(9.32 \%)$ after meals & $36(15.25 \%)$ good habit \\
\hline & & \multirow{5}{*}{$\begin{array}{l}\text { Materials used in } \\
\text { brush }\end{array}$} & 36(15.25\%) Toothpaste & $30(12.71 \%)$ Not known \\
\hline & & & 20(8.47\%) Kalo Majon & 15 (6.36\%) No opinion \\
\hline & & & 120(50.85\%) Ash & $85(36.01 \%)$ cheap cleaner \\
\hline & & & 48(20.34\%) Neem stick & $22(9.32 \%)$ Prevent decay \\
\hline & & & 12(5.08\%) Magic powder & 08 (3.39\%) Better cleaner \\
\hline & \multirow[t]{2}{*}{ Smoking habit } & Yes & $30(12.71 \%)$ & $30(12.71 \%)$ No answer \\
\hline & & No & $206(87.29 \%)$ & $\begin{array}{l}206(87.29 \%) \text { bad for } \\
\text { health }\end{array}$ \\
\hline & \multirow{2}{*}{$\begin{array}{l}\text { Nail keeping/ } \\
\text { trimming }\end{array}$} & Short nail & $198(83.00 \%)$ & $220(93.22 \%)$ no disease \\
\hline & & Long nail & $38(16.10 \%)$ & $16(6.79 \%)$ no comment \\
\hline & \multirow[t]{2}{*}{ Bathing } & Regular (daily) & 201(85.17\%) & $\begin{array}{l}\text { 201(85.17\%) fresh, } \\
\text { cleans body }\end{array}$ \\
\hline & & Not regular & $35(14.83 \%)$ & $35(14.83 \%)$ no answer \\
\hline & \multirow[t]{2}{*}{$\begin{array}{l}\text { Wearing } \\
\text { underwear }\end{array}$} & used & 196(83.05\%) & $\begin{array}{l}\text { 104(44.07\%) prevents } \\
\text { itching }\end{array}$ \\
\hline & & Not used & $40(16.95 \%)$ & $10(4.24 \%)$ not known \\
\hline & \multirow[t]{2}{*}{ Exercise } & Regular & $20(8.47 \%)$ & $\begin{array}{l}48(20.34 \%) \text { good for } \\
\text { health }\end{array}$ \\
\hline & & Not regular & $216(91.53 \%)$ & 188(78.66\%) no answer \\
\hline & \multirow{2}{*}{$\begin{array}{l}\text { awakening } \\
\text { habit }\end{array}$} & Before the sun rise & $36(15 \%)$ & - \\
\hline & & $\begin{array}{l}\text { After the the sun } \\
\text { rise }\end{array}$ & $200(84.74 \%)$ & - \\
\hline
\end{tabular}

A very low percent of respondents (4.24\%) used soap for washing of hands after defecation. About $95.76 \%$ of students reported that they washed their hands with water only and soaps were seldom used. Nevertheless the majority of students (85.59\%) admitted that washing of hands before meals and after defecation yielded good effect and there was always benefit from prevention of disease occurrences. The findings with respect to oral hygiene practice, $55.08 \%$ respondents preferred to brush teeth before going to bed at night, followed by a lesser number of respondents (36.87\%) who brushed usually in the morning and only a few number of respondents had the tendency to brush their teeth after lunch time at mid-day. A good number of respondents $50.85 \%, 20.34 \%, 15.25 \%, 8.47 \%$ and $5.08 \%$ used ash, followed by neem stick, tooth paste, Kalo Majon and magic tooth powder respectively. The present study obviously traced development of bad habit among some students and that is smoking habit. Although $87.29 \%$ of respondents never smoked, but it is very undesirable that more than $10 \%$ of students developed smoking habit 
which they agreed to be injurious to health but made no answer. To non-smoker students smoking is a bad habit which is very much detrimental to health.

The present study revealed that $83.00 \%$ of respondents were in favor of keeping nails short. They indicated trimming nail and keeping short could protect persons from diseases. Regarding personal cleanliness $14.83 \%$ of the students reported not taking bathing regularly and this is a poor hygiene practice. It is however encouraging that the majority students $(85.17 \%)$ under this study to keep them clean and fresh were very much accustomed to take bath regularly. These students (83.05\%) realized the importance of wearing underwear, but only $44.07 \%$ knew about the benefit of underwear which they pointed out as might prevent itching. Table 3 further demonstrated that the students under interview although clearly stressed upon the need of regular exercise which is good for health, but quite a big number of respondents (91.53\%) were not inclined to take exercise regularly.Regarding the practice of rising from sleep at morning majority students (84.74\%) reported that they practiced it after the sun raised; while a small percent habituated to rise from sleep before the sun rise.

\section{Discussion}

This cross sectional type of descriptive study conducted among the semi-urban secondary school students of sample size 236 with mean age 14.h years with SD \pm 2.3 .The study provides insights into the activities of the school students concerning the approach, materials and methods of the health and hygiene. This knowledge is necessary for the practice of proper hygiene in the school environment. The result of the present study depicted that the level of knowledge on health and personal hygiene within the Bangladeshi society is not only poor but limited. The precise factors linking to interventions under this study are (i) washing of hands before meals and after defecation with soap and water (ii) awareness about health and sanitation (iii) personal hygiene (iv) eating and drinking habit $(v)$ tooth brushing practice and bathing habit (vi) sleeping time (vi) smoking, nail keeping and underwear use (vii) physical exercise. Poor hygiene and health practices restricts the socio-economic, psychological and health wellbeing of adolescents. This case-study focuses on a health and hygiene school program initiative. Interpretation can be drawn from the findings of the investigation that ignorance and indifferent to hygiene practices and inadequate sanitary conditions as focused from oral expression of students under the present study could lead to increased burden of communicable diseases. This study evaluated the general knowledge of health and practices of hygiene among semi-urban school children in Bangladesh and assessed the extent to which proper knowledge of hygiene was associated with personal hygiene characteristics.

Health and hygiene education is important and effective because of it's simplicity hygienic activities, such as hand-washing with soap, may prevent many of these diseases. Four health-related Millennium Development Goals (MDGs) address poor sanitation, unclean water, lack of personal hygiene and other health related issues. To improve health in urban slums, intervention programs with hygiene promotion remain important. Since more than half of the student population in this study were although having limited knowledge about personal hygiene and protection of health, but our findings of the present investigation concluded that a health education program in urban, semi-urban and rural areas in Bangladesh definitely could play highly significant improvements in knowledge, water and sanitation facilities and personal hygiene. The findings of our study clearly demonstrated that hygiene practices are heavily influenced by students' knowledge and attitudes towards hygiene. Reasons given for not washing hands included stubbornness (not wanting to follow what adults say), laziness, the time it takes away from playing, and the dirt. Despite these negative attitudes towards hand washing, more than $85 \%$ students practice good hand washing behavior. Although the students know that washing hands after defecation is important, they may be negatively influenced by factors such as laziness, the rush to play with friends, or even the lack of hand washing 
facilities close to the latrines. Most students reported hand washing using water before meals $(91.53 \%)$, but only $8.47 \%$ reported using soap which is less than the findings of Alyssa et $\mathrm{alP}^{8 \mathrm{P}}$. Although $95.76 \%$ of students reported that washing hands with water after defecation was important, but only $4.24 \%$ reported actually following this practice using soap. Notably, the self-reported frequency of hand washing before meals among children in our study is substantially lower than frequencies reported from studies of children in other countries ${ }^{8 \mathrm{P}}$ and higher than the study of Nuzhat Chowdary and Mohammad Awlad Hossain $P^{9 P}$.

Hand hygiene studies conducted in other countries $^{8 \mathrm{P}}$ have indicated that children with proper hand washing practices are less likely to report gastrointestinal and respiratory symptoms. The low frequencies of hand washing with soap may be attributed to the lack of soap in school and at home. Soap, water, and latrines are essential for proper hygiene practice in schools. Another reason that can influence hygiene practice among school students is the low level of parental literacy. Importantly, Bangladeshi and foreign global public health agencies have been taking steps towards enhancing access to resources and to increase health literacy particularly concerning sanitation and hygiene. In 2007, UNICEF launched the Water, Sanitation, and Hygiene (WASH) Program which is designed to promote hand washing and sanitation practices in low income countries including Bangladesh. Regarding the oral hygiene, students adopted improper tooth brushing methods which are comparable with other forein studies $\mathrm{P}^{10-12}$ $P$ and they did it due to insufficient oral hygiene and frequency of tooth brushing knowledge which is also comparable with forien studies $\mathrm{P}^{13,14 \mathrm{P}}$.

The present study revealed that the students had poor status regarding knowledge, attitudes, and practices of hygiene. Approximately $\quad 50-60 \%$ of students investigated did not know about the possible transmission of diseases through human waste. Approximately, one-seventh of the students were reported not bathing regularly, that is they were within boundary line of poor hygiene practice. Similarly, approximately $16 \%$ kept long nail without trimming, 17\% not using under wear, $12 \%$ having smoking habit which was less than the findings of Katulanda et alP ${ }^{15 P}$, and although most students practiced brushing their teeth, but only 15\% used tooth paste. These data clearly demonstrated that these students were not following were the least common hygiene practices.Behavior change of the community has been focused as key strategic area for sustainable hygiene and sanitation practice. In terms of sanitation practices, certain indicators like use of improved sanitation practices, reduced open defecation, safe disposal of child feces, wash both hands at critical moments are considered to measure the behavior change of the community. UNICEF and other agencies already launched the Water, Sanitation, and Hygiene (WASH) Program which is designed to promote hand washing and sanitation practices in low income countries including Bangladesh. Additionally, the Bangladesh Ministry of Health recently implemented a National Millennium Hygiene and Sanitation Movement Program. These initiatives, coupled with well developed school-based health and hygiene curricula that promote improved personal hygiene at home and at school should contribute to better health and hygiene conditions among school children. Since in developing countries like Bangladesh, improvement of the hygienic practices are considered not only vital but also cost effective in order to promote basic health requirements, and since many of the unhealthy practices are considered to be the consequences of ignorance and prejudice. Empirical evidence also suggests the importance of hygienic practice and health related behavior in reducing the extent of such diseases and deaths significantly. As researchers have found 2,16,17P that inadequate hand washing after defecation and anal cleaning was prominent source of transmission of enteric diseases in the countries like Bangladesh. Education has the potential to significantly alter the behavior patterns of students and can thereby lead to improved outlooks on hygiene. Much of hygiene practices are contingent upon availability of sufficient resources. Welldesigned and well-located hand washing facilities and latrines that include adequate amounts of soap and water, are essential in 
Original Article

promoting hygiene. If hygiene intervention programs implement, these two important factors-education and resources-the needs of students can be better met and can thereby result in decreased risk of disease.

\section{Conclusion:}

Interactive and participatory classroom sessions, providing school students with information ranging from basic hygiene to the effects of personal hygiene should be arranged. It is hoped that session program will result in an increased health and hygiene awareness among students and changes in behavior related to sanitation, food intake and hygiene practices. Health and hygiene education programs are especially important in children living in semi-urban and urban slums, as they are at risk of many diseases, including soil- and water-transmitted intestinal parasites, because of poor sanitation, unclean water, and lack of personal hygiene. School-based hygiene education may decrease the rates of transmissible diseases. Children are more receptive to learning and are very likely to adopt healthy behaviors at a younger age. They can also be agents of change by spreading what they have learned in school to their family and community members. Future studies should specifically assess the attitudes that students have towards hygiene, availability of water and sanitation facilities at home and at school, and the reasons behind hand washing. Enhanced, comprehensive knowledge about these issues should be used to improve lowcost but highly effective programs that will meaningfully attenuate the burden of transmissible disease among students in semi-urban and rural settings.

\section{Acknowledgement:}

I am ever grateful, indebted and enormous thanks to Professor Dr.M.Mufizur Rahman, Prof. (Rtd) Dept.of Microbiology \& hygiene, Agriculture University Mymensingh for his scholastic, sincere effort for prepared this investigation fruitful. I also expressed my gratitude to my other co-authors for their sincere works and guidance.

\section{References}

1. K.PARK, PARK'S Text Book Of, Preventive and Social Medicine, 20th Ed,Feb/2009, M/S Banarsidas Bhanot Publisher.1167, Prem Nagar,.PJABALPUR,48200M India.Page43.

2. UNICEF to Launch World hand-washing day,
3. UNICEF/Philippines/2009/Vivar-www. unicef. org. philippines /8892_10726. html,

Accessed 17Aug/ 2011.

4. World Hand Washing Day celebrated nation.com.pk/..../Lahore/15-oct-2011/world hand- washingday Celebrated. Accessed; JAN $10, .2012$

5. Curtis VA, Danquah LO, Aunger RV. Planned, motivated and habitual hygiene behaviour: an eleven country review. Health Educ Res. 2009; 4:655-673

6. United Nations Children's Fund Soap, Toilets, and Taps. A Foundation for Healthy Children. Accessed Nov 5, 2010.

7. S. A. Ahmed, water \& sanitation programme,personal communication April 2002, based upon "Health care expenditures in Bangladesh" in "Health situation and health care expenditures in Bangladesh,evidences from nationally representative survey"BBS April 1999.

8. Alyssa Vivas, ${ }^{a}$ Bizu Gelaye, ${ }^{a^{*}}$ Nigusu Aboset, ${ }^{b}$ Abera Kumie, ${ }^{c}$ Yemane Berhane, ${ }^{b c}$ and Michelle $\quad A$ Williams ${ }^{a P}$ Knowledge, Attitudes, and Practices (KAP) of Hygiene among School Children in Angolela, Ethiopia; J Prev Med Hyg. 2010; 51(2): 73-79.

9. Nuzhat Choudhary, Mohammed Awlad Hossain-exploring the the current status sanitary latrin use in Shibput upazila, Narsingdi district, BRAC Research Report November 2006.

10. HHsieh HJ, Huang ST, Tsai CC, Hsiao SY. Tooth brushing Habits and Risk Indicators of Severe Early Childhood Caries among Aboriginal Taiwanese. Asia Pac J Public Health.2012 Mar16.

11. HOlmez S, Uzamiş M, Erdem G.Association between early childhood caries and clinical, microbiological, oral hygiene and dietary variables in rural Turkish children. Turk J Pediatr. 2003; 45(3):231-6.

12. HRajab LD, Petersen PE, Bakaeen G, Hamdan MA. Oral health behaviour of school children and parents in Jordan. Int J Paediatr Dent. 2002; 12(3):168-76.

13. HFinlayson TL, Siefert $K$, Ismail Al, Sohn W. Psychosocial factors and early childhood caries among low-income African-American children in Detroit. Community Dent oral Epidemiol.2007; 35(6):439-48.

14. Alm A. On dental caries and caries-related factors in children and teenagers. Swed Dent JSuppl.2008; (195):7-63,

15. HKatulanda $P$, Liyanage $I K$, Wickramasinghe $K$, Piyadigama I, Karunathilake $\mathrm{IMH}$ almer $\mathrm{PH}$, Mathews DR. Tobacco Smoking Among School Children in Colombo District, Sri Lanka. Asia Pac J Public Health. 2012 Mar 16. 22426558

16. Key Points, Chapter 6, Hand Hygienewww.travmed.com _ guide/ch6.htm, Accessed 5July/2011.

17. MJ Hygiene services-Food Safety Articles $6^{\wedge}$ WHO! Food Safety and foodborne illness. who int. retrieved on 2010-1210.7,Accessed 2 Jan/2012. 